\title{
What Students Learn about Recognizing Children's Capability
}

\author{
Mag Alina Georgeta \\ Teacher Training Department, University “Lucian Blaga” of Sibiu, Sibiu, Romania \\ Email: alina.mag@ulbsibiu.ro
}

How to cite this paper: Georgeta, M. A. (2018). What Students Learn about Recognizing Children's Capability. Creative Education, 9, 2445-2454.

https://doi.org/10.4236/ce.2018.915184

Received: September 26, 2018

Accepted: November 11, 2018

Published: November 14, 2018

Copyright $\odot 2018$ by author and Scientific Research Publishing Inc. This work is licensed under the Creative Commons Attribution International License (CC BY 4.0).

http://creativecommons.org/licenses/by/4.0/

\begin{abstract}
Recognition of the role and contribution to children's learning and development of those who are trained to work in the early years is long overdue and welcomed, although the contentiousness and questions of how to prepare students still need to be addressed. The aim of this study was to investigate what disciplines from the curricula of the Teacher Training Department, inside "Lucian Blaga" University of Sibiu allow students to identify the effective ways of recognizing children's capabilities. The methods used were interview, observation and focus groups. 20 teachers and 50 students were engaged with this challenging work. The qualitative analyses of the data collected proved that this topic is mainly mentioned, but not enough trained. Findings revealed that curricula need serious improvements to prepare students to meet the needs of children. The focus groups organized allow teachers and students involved to reflect on their own ideas, experiences and ways of practicing. The study offered opportunities to reflect on new ways of teaching and learning, to support students with a curriculum that highlights children' rights and capabilities.
\end{abstract}

\section{Keywords}

Children's Capability, Rights' Perspectives, Challenges, Contemporary

Research, Curricula for Training Teachers

\section{Introduction}

Attitudes towards children are changing, through the growth of new attentions to children's needs and capabilities. The impetus for change is energetic and powerful. One of the key ideas producing change is the premise that traditional education was silencing children. Different forces present in many societies have made children being seed by adults in terms of stereotypes based on them being 
incapable or untrustworthy, vulnerable or dependent. These attitudes are being challenged and changed. Recent research driving by the rights' perspectives is seeing children as competent, active and engaged participants in their own lives (Jones, 2009). The attention to children being seen and listened to, rather than as a part of their family, or through the filter of their parents, is giving new insights into the ways future early childhood teachers need to be trained.

Teachers' training systems all around the world need to adjust the disciplines to these current realities of children's lives. The challenge for teachers and students undertaking further professional development is to develop a critical and analytical perspective towards their practice to uncover new professional insights. Professionalism in early childhood education can be difficult to define. The ways in which early years' practitioners become competent, knowledgeable and skillful will continue to be many and varied (Cable, Miller, \& Goodliff, 2010). Students that are trained to become teachers are required to graduate being able to demonstrate that they can meet a set of national standards covering the areas: knowledge and understanding, effective practice, relationships with children, communicating and working in partnerships with families, teamwork and collaboration and professional development. Each country highlights the need for early years' practitioners to be well prepared. Those working with children, all over the world, need to be skilled and knowledgeable.

Reflections upon practice and learning during the initial training of students are an important dimension of the early years' practitioners' role. Teachers have the power to make a major difference to children's lives and their development by what they offer children and by how they behave towards them. Students need to be aware of the kind of attitudes that are indeed respecting children's needs and rights, through all their training efforts, to become well-prepared teachers for the new generations of children.

\section{Problem Statement}

There have been many ways of describing and analyzing childhood. Within different cultures and across different time periods there have been a variety of ideas and concepts concerning the state of human development and experience that we currently name "childhood". This occur through a dynamic interplay between spoken and unspoken assumptions about what children are and are not, what they may and may not do, how adults can and cannot act in relation with them (Jones, 2009). This study looks at the challenges of the teacher training system in Romania to emphases issues concerning children's capabilities, during the academic preparation of students. According to the traditional views, children were considered innocent, or passive and incapable. The ways those working with children see and think they see, what children can and cannot do, have recently been questioned (Cable, Miller, \& Goodliff, 2010). The issue of how competence and capability can be defined and seen is complex. The notion of incompetence is based on notions of capacity and competence: "many children 
will be competent if information is presented in an appropriate way and they are supported through the decision-making process" (Jones, 2009).

The rhetoric of much adult attention to childhood creates it as a time when many societies like to perceive children as "care free" or innocent. The picture fed back by research creates very different accounts of childhood. UNICEF (2007: p. 32), for example, refers to its recent findings as a "shadow" on this traditional image: "making the time of life that adults like to think of as happy and carefree into a time of anxiety and misery". This shadow is linked to the exclusion and deprivation-both material and emotional-faced daily by many children. A key element of this is the way in which adult actions and perceptions, fueled by their attitudes towards childhood, silence and exclude children. Silencing and exclusion create different effects through their entire future development. The UNICEF Young Voices Poll in 2001 surveyed children's experiences through interviews with 15,200 children between the ages of 9 and 17 years in over thirty-five countries. When asked about "rights" for children, more than a third spontaneously mentioned the right not to be hurt or mistreated as being important, with the same percentage saying they felt that this right was not respected in their country. Many of the negative findings relate to adult attitudes and ways of relating to children. Lots of children confessed that they faced violence or aggressive behavior, that their views were not sufficiently considered, or not considered at all by local government (UNICEF, 2001).

Researchers have indicated that preconceived views often contain negative views of children that restrict and damage them. Kemshall (2008: p. 22), for example, comments that young people are often characterized as "imprudent, irrational and hence vulnerable, by failing to calculate risks properly or to act wisely". From a historical, cultural perspective such long-held views that see children in certain ways conflict with a powerful, emerging set of pictures which oppose tradition, and which offer new ideas and opportunities to children and society. Authors such as Redmond (2008) see the rights perspectives as having a dual purpose which connects with the re-viewing of such negative pictures and attitudes towards children:

- to extend the fundamental human rights recognized for adults to children, and to challenge the forms of exclusion and exploitation they can face;

- to call attention to children's status about specific interests, entitlements and vulnerabilities (Redmond, 2008: p. 64).

Often citing the UN Convention (1989) as an impetus, several countries are introducing laws, policies and practices within areas such as education, health and play which try to engage with some of the tensions created by these new ideas and pictures of children. The ideas offer a challenge to adults within many roles and relationships, and in many spheres of action and activity. These new pictures and ideas work against stereotypes and the assumptions many adults make in their dealing with children.

Ideas about limitations set by adults, based on their ideas of what children can 
and cannot do, are being questioned. Notions based automatically on age, that assume children are not able to make decisions are being held up to scrutiny. The idea that childhood should be a time where responsibility is held by others because children are deemed to be innocent, or too immature, or incapable is being challenged. Are children capable or incapable? Do adults' attitudes encourage and reinforce the image of children as incompetent? How do such attitudes affect their lives? In addition to the focus of research, innovations are being made in the way research is conceived and carried out. Its role in children's lives is changing. In the past many studies treated children as objects: research was done on them, with the agenda and framework set purely by adults. Nowadays children create the way research is conceived and carried out. Children act as researchers, researchers work with questions formulated by children or work with children in new ways drive by rights perspectives (Jones, 2009).

MacNaughton et al. (2007) researched about adult stereotyping regarding age and capability and looked at how to consult children aged between 3 and 4 years of age and gender policy in preschools. They found that this was possible by finding appropriate ways to communicate with, and to establish the children's ideas and views. They conclude that their case study work reinforces the "grow body of research evidence that young children are quite capable of expressing their views on things that affect them" (2007: p. 465). Different ways in which widely held attitudes have a negative effect on children's lives were analyzed in several studies: from the notion that children are incapable, through to ideas that children are a threat. Also, different relationships with children can create positive experience, outcomes and practices.

These new directions have drawn on the United Nations Convention on the Rights of the Child and its concepts of protection, provision and participation. Recent research offered illustrations about adopting a right-based approach to the evolving capacities of the child and the environment created to promote and respect children (Moss \& Petrie, 2002). Moss talked about the importance of listening and consulting children but acknowledged that this is a complex process. Listening and consulting must consider of power relations and their inequalities between adults and children. Children's otherness, their difference, offers a challenge to adul-orientated norms of identity, and to contemporary ideas about key areas of social and cultural experience such as education, play, work and decision making. Another key point is an emphasis on children as active agents in their lives. Connected to this is the movement to enable children to change the ways they participate and have an impact in different areas of society: from government to home life (Cable, Miller, \& Goodliff, 2010).

The tendency within recent academic discussion and within research is to examine "such versions or imagines of childhood", often described as ways of understanding childhood, as being socially constructed. They show that there are different kinds of childhood, that these have changed over time and that they are different between, and within, different societies and cultures. Summarizing 
the recent studies that are analyzing childhood, today children are active agents in their own lives and able to contribute and participate in decision making (Jones, 2009).

The development of o more professional workforce is an evolving process and considerable progress has been made in the last decade. Cable, Miller and Goodliff (2010) argue that as a workforce which is gaining increasing recognition and access to professional development opportunities, early years practitioners have a unique responsibility to influence children's learning and development. Recognizing children's capabilities, for a healthy development, learning and well-being of children must be at the heart of what they do.

\section{Research Question}

In the field of teacher training, there are lots of preconceived ideas, traditional principles and inadequate activities, with good intentions, that create big obstacles for an efficient learning process. Students that are trained to become teachers need to understand that children love to be involved as active and capable participants in the learning process. They must learn to put the child in the center of the educational system. The meaning of teaching is not to keep great lectures, but to help children to go through an efficient transformation (Stolovitch \& Keeps, 2017).

The academic curricula of training today's teachers for preschool and primary education in the Romanian system is verified, to understand if the contemporary tensions in childhood are up to date. Driven by the increased attention to children's rights and needs, the research question is: what students learn about recognizing children capabilities, to fulfill their rights and needs, through the curricula of the university "Lucian Blaga" of Sibiu? The focus is on a sensitive theme that brings teachers and students together to reflect on the meaning and quality of their work, because the way students are prepared is essential, to be able to face the educational needs of today's children.

\section{Purpose of the Study}

The aim of this study was to find out what disciplines from the curricula of Pedagogy of Primary and Preschool Education, from the Teacher Training Department inside "Lucian Blaga" University of Sibiu, aloud students to identify the effective ways of recognizing children's capabilities. A group of 20 teachers and 50 students, selected from each academic year of studying, were engaged with this challenging work. Driven by the research question formulated, they analyzed together the academic curricula. Teachers and students were voluntarily involved: 15 students representing the first year, 15 students from the second year and 20 students representing the final year of preparation. The disciplines selected for this investigation were: The Fundamentals of Pedagogy, The Fundamental of Psychology, The Theory of Information and Communication, Curriculum Theory and Methodology, Psychology of Ages, Educational Psychology, 
Romanian Literature, Literature for Children, Mathematics for Primary and Preschool, History of Pedagogy, Early Childhood Education, Inclusive Education of Children's with Special Needs, Psychology of Personality, Ethics, Class Management, Psycho-pedagogy of Game, The Methodology of Educational Research, Professional Practice in Preschools and Professional Practice in Primary schools. Each group of students was encouraged to freely express their opinions, to reflect together with their teachers on the relevance of their common efforts focused on the theme approached.

\section{Research Methods}

The question of this study helped students and teachers to interrogate their own attitudes and beliefs about children's capabilities in a challenging and constructive way. The investigation was developed during the academic year 2017-2018, using three research methods: interview, observation and focus groups. The theme analyzed is essential for those studying childhood at graduate level, because their attitudes and deep understanding on children's potential and needs will be reflected in their future work with children. The debate between teachers and students from the perspective of each discipline they studied took place at the end of each semester. Thoughts and opinions were provoked through examples from the courses and seminars, reflections, activities and key points that helped students and teachers to become aware if their initial training was or was not properly accorded to the current perspectives on children and childhood, about recognizing children's capabilities.

\section{Findings}

This study used a qualitative approach to examine all the participants' reflections and answers recorded to investigate the different ways of recognizing children's capabilities trained through the disciplines of the academic program-Pedagogy of Preschool and Primary Education, in the University of Sibiu, Romania. The research question was addressed through a series of focus groups, including the courses documents analysis and the interviews with students and teachers. The investigation focused particularly on the theoretical and practical content of each discipline in relationship with recognizing children's potential.

At the beginning the participants discussed the current trends in children's education: young children have needs and vulnerabilities, but the way in which children are seen by adults has come to emphasize seeing the child as a serious of needs, but mainly as having potentials and capabilities. Issues concerning adult attitudes that allow participation, but deny any actual impact of children's involvement, was a complex theme that helped teachers and students examine the way teaching and learning each discipline included children's voice and potential. Each teacher of a certain discipline received a prolific feedback from the groups of students that recently studied the discipline analyzed from the research 'question point of view. 
First, they checked the content of each discipline curricula, trying to find if this theme was approached as a topic. Using observations on the listed courses, they discovered that just a small number of disciplines mentioned it, like: Early Childhood Education, Ethics, Inclusive Education of Children's with Special Needs and Educational Psychology. Findings proved that different ways of recognizing children's capabilities were mentioned especially through seminar debates, by just a few teachers. Teachers and students responded to an analytic interview about their teaching and learning. They realized that such a sensitive theme was not enough prioritized during their courses and seminars. The aim of the focus groups was to emphasize the necessity of preparing students to understand the huge impact of children's potential. Teachers and students were encouraged to reflect on their common efforts' impact and to the quality of their work.

Each teacher was focused primarily on the discipline content, but during the debates they came to the conclusions that theoretical data were not enough if students were not linked constantly to children's needs and rights in real life. Students' initial training is a process of acquiring knowledge, attitudes and skills to become responsible and competent teachers. Most of the teachers involved in the study realized they should support their students to learn how to develop responsible attitudes focused on children's capabilities, as a priority.

During their professional practice in Preschools and Primary Schools, students had the chance to work with children with different capabilities, so they realized that their teaching efforts are effective only if they respect children's potential. Teachers and students involved in this study reflected on the need to prioritize children's capabilities, as a relevant part of improving children's lives. During the focus groups they connect to the next certain emphases, that all disciplines need to include: asking children directly for their views, to discover and respect each child's capacity.

Teachers and students reflected on children's empowerment as active agents in their own lives and they realized that most of the disciplines were not focused on this. Children need to be recognized as competent, and they can make a unique contribution to the understanding of their childhood. It's important for students to be engaged through debates and reflections around this reality, for a responsible initial teacher training. Professionals in early childhood education need to be properly trained to respect children's needs and rights. Seminars and courses of all disciplines need to include relevant training about children's capabilities. This emerging necessity is not without its challenges and difficulties.

The content of the disciplines analyzed were systematically observed and questioned. The respondents realized that "children's voice" is one of the specific ways of recognizing their capabilities. Findings revealed that this topic was only mentioned by a few disciplines: Early Childhood Education, Educational Psychology, Practice in Preschool, Practice in Primary Education and Ethics, but not enough trained. Most of the disciplines mainly mentioned this recent view in 
today's education, so students remain insufficiently prepared. During the focus groups, the respondents came to highlight the need for the teacher training institution in Romania to include in their curricula more relevant themes to respect children's rights and children's voice, as some of the relevant ways to recognize their capabilities from early ages. The reform still needs improvement and teacher education still needs change.

The analysis of findings which have tried to name and to understand what is missing from our teacher training curricula reveals that teachers need to adjust their disciplines and to change their mentalities about the involvement of children, to ensure their voices are both listened to and acted on. Students must be trained to listen to children's voice, to be able to deeply understand their unique capabilities. Research, thinking and practice are enquiring to see children's lives in new ways, into ideas of their capability, to end silencing and fearing them by adult's power. The academic curricula need a relevant improvement, driven by the increase attention to the rights' perspective.

Students and teachers involved realized that through teaching and learning each discipline they should focus more upon this area of change, exploring new ways of living and working with children, and exploring children's responses, ideas and experiences as new approaches, ideas and ways of recognizing children's capabilities. The disciplines that are not including enough focus on children's voice and capabilities have been identified as in need to be improved. All the debates were around challenging adults' attitudes and practices involving children, and on emphasis on children as active agents in their own lives. The qualitative analyses of the data collected also proved that our national curricula offer lots of traditional disciplines, and the theoretical part is oversized in relation to practical training.

Findings revealed that the contemporary ideas about children's rights and needs are present in different contents of only a quarter of disciplines, but most respondent students confessed they need more training about these topics to understand the roles children have in their lives and education. Students need more materials from recent research in their theoretical and practical preparation, to be helped to challenge negative attitudes and to see how different relationships with children can create positive experiences, outcomes and practices. These new directions drowned by the United Convention on the Rights of the Child and its concepts of protection, provision and participation need to be in the attention of each teacher, no matter what discipline they teach. The respondent teachers realized they need to adopt a "rights-based approach" to the "evolving capacities" of the child and to create the teaching-learning environments to promote and respect children, for a proper training of their students.

Teacher trainers involved in the study reported few courses and little general training in using the new trends in understanding children in practice. Nevertheless, mastering the new ideas about children and childhood at a theoretical level does not necessarily provide student-teachers with new insights about how 
to teach and learn, or to become competent in today's children education. The importance of listening and consulting children was highlighted in the final debates of the participants. Listening and consulting children are significant ways of recognizing their capabilities, to ensure children's rights are realized.

These contemporary ideas were offered to students in general courses or seminars, but with no individual instruction to apply them in practice. Students need demonstrations of some key responses to ways of challenging attitudes that silence children, see them as incapable, end exclude them from participation and decision making. Teachers involved in the study realized they must do more in teaching each discipline to offer insight into ways of relating to children that sees them as capable, competent agents involved in decision making and having opinions that count. The teachers and the students involved in this investigation considered that the value of the teacher training curricula depends on the accent of these contemporary topics during their theoretical and practical preparation. During the focus groups with all respondents, the following aspects were highlighted:

- the understanding of contemporary ideas' implementation through each discipline from the academic curricula includes skills, knowledge, creativity and attitude fit for today's generation of children;

- new ways of teaching and learning, thinking and behaving can facilitate a proper training for students.

Findings revealed that trainers' attitudes, skills and practices need to follow the contemporary ideas in early childhood education, for applying the academic curricula more efficiently, so that students to be well prepared for the children's of today.

\section{Conclusion}

The issue of how competence and capability can be defined and prioritized is complex and essential for the teaching profession. This study has drawn attention to the way children's capability needs to be considered by the academic curricula of preparing future teachers. It is important to provide students at all levels with comprehensive training so that they can become responsible future teachers.

In a national context, teacher training offered in the University of Sibiu is considered solid and traditional. Conclusions revealed that curricula need serious improvements to offer students access to some of the challenges, discoveries and work in progress of contemporary research. Future teachers are encouraged to become aware of current perspectives on children and childhood, to develop a critical relationship with the content of each discipline they study, and to develop their own reading of childhood. All those working with children need to recognize children's potential, from early ages.

\section{Conflicts of Interest}

The author declares no conflicts of interest regarding the publication of this paper. 


\section{References}

Cable, C., Miller, L., \& Goodliff, G. (2010). Working with Children in the Early Years (2nd Edition). London: Routledge Taylor \& Francis Group.

Jones, P. (2009). Rethinking Childhood. New York: Continuum International Publishing Group.

Kemshall, H. (2008). Risks, Rights and Justice: Understanding and Responding to Youth Risk. Youth Justice, 8, 21-38. https://doi.org/10.1177/1473225407087040

MacNaughton, G., Hughes, P., \& Smith, K. (2007). Young Children's Rights and Public Policy: Practices and Possibilities for Citizenship in the Early Years. Children and Society, 21, 458-469. https://doi.org/10.1111/j.1099-0860.2007.00096.x

Moss, P, \& Petrie, P. (2002). From Children's Services to Children's Spaces: Public Policy, Children and Childhood. London: Routledge.

Redmond, G. (2008). Child Poverty and Child Rights: Edging toward a Definition. Journal of Children and Poverty, 14, 63-82. https://doi.org/10.1080/10796120701871298

Stolovitch, H. D., \& Keeps, E. J. (2017). Formarea Prin Transformare: Dincolo de prelegeri. București: Editura Trei.

UNICEF. (2001). Young Voices Poll. http://www.unicef.org/newsline/01pr42.htm

UNICEF. (2007). Child Poverty in Perspective: An Overview of Child Well-Being in Rich Countries. Innocenti Report Card 7, UNICEF Innocenti Research Centre, Florence, United Nations Children's Fund. 